Canadian Journal of Family and Youth, 6(1), 2014, pp 163-187

ISSN 1718-9748 @ University of Alberta

http://ejournals.library.ualberta.ca/index/php/cjfy

\title{
The Influence of Family Context on Adolescent Depression: A Literature Review
}

\author{
Caroline Marshall and Joanna Henderson
}

\begin{abstract}
Family context has been shown through empirical studies to be a central determinant in the mental health of youth throughout the past decade. In this analysis we examine the association between attachment, parental depression, divorce, family climate, and siblings, and the risk of adolescent depression. Conclusions are made regarding the complex nature of family situations, and specific improvements and suggestions for future studies of the effects of family situation on adolescent depression.
\end{abstract}

Caroline Marshall is a high school student from Toronto, Ontario, Canada. She completed a 5-week student placement at the Centre for Addiction and Mental Health in the summer of 2013 and is currently attending boarding school at the Institut Le Rosey, Rolle in Switzerland.

Joanna Henderson is a Clinician Scientist at the Centre for Addiction and Mental Health and Assistant Professor of Psychiatry at the University of Toronto. Dr. Henderson's research interests include youth substance use and mental health, trauma, youth risk-taking, help-seeking behaviour, and innovative models of knowledge translation and exchange. Publications include:_Henderson J, Brownlie EB, Rosenkranz S, Chaim G, \& Beitchman J. "Addressing the research-practice gap through stakeholder involvement in grant proposal development." Journal of the Canadian Academy of Child and Adolescent Psychiatry. 22(4), 268-274; Rosenkranz S, Muller RT, \& Henderson J. "The role of complex PTSD in mediating childhood maltreatment and substance abuse severity among youth seeking substance abuse treatment." Psychological Trauma: Theory, Research, Practice \& Policy, 2013. doi:

10.1037/a0031920; Henderson J, Milligan K, Niccols A, Thabane L, Sword W, Smith A, \& Rosenkranz S.

"Reporting of feasibility factors in publications on integrated treatment programs for women with substance abuse issues and their children: A systematic review and analysis." Health Research Policy and Systems. 2012:10(37). 


\section{Overview}

Research shows that the development, persistence, and pathways of depression in adolescents are impacted by family situations (Sander and McCarthy, 2005). From infancy, parents play a pivotal role in a child's life, socializing them emotionally, mentally, and physically. As a result, many researchers have analyzed how this fundamental relationship unfolds to impact adolescent depression. Family systems are highly complex and can be affected by a number of influencing factors that initiate and/or perpetuate depression in adolescents. This literature review examines previous literature focused on the relationship between family context and adolescent depression and will outline some of the key areas scientists are targeting in their research both in identifying patterns and speculating on the mechanisms at work.

\section{Attachment}

A significant factor that has been analyzed in studies related to adolescent depression is the effect of parental attachment on youth. Bowlby's (1980) Theory of Attachment suggests that the links that are made in childhood with adults create expectancies in children for future relationships. Insecure attachment promotes a negative sense of self-worth, planting the feelings of being unworthy of love and pessimistic that others will meet emotional needs (Bowlby, 1980). Since the support offered by parents in this situation does not meet the children's needs, children expect that other people in their lives will also be unable to provide meaningful support, creating a belief that support-seeking is a futile coping strategy (Shirk, Gundmenson, and Burwell, 2005). These perceptions coupled with the lack of support seeking can in turn contribute to the development of depressive symptoms. In a study by Armsden et al. (1990), depressed and nondepressed youth were surveyed on attachment and depressive symptoms. Their findings suggest that as the severity of attachment issues increases, the severity of the depressive symptoms in the 
adolescents also increases. In 1995, Hammen and colleagues observed a similar relationship between attachment and depression in 155 adolescent girls. Their study, however, only focused on female high-school seniors due to the higher rates of internalizing symptoms experienced by girls over boys during this developmental stage (Kandel and Davies, 1986; Nolen-Hoeksema and Girgus, 1994; Hankin and Abramson, 2001), so their conclusions cannot be extended to other adolescent groups. Hammen et al. (1995) suggested that the relationship between attachment and depression might be due to the increased vulnerability of insecurely-attached youth to interpret stressful life events such as rejection, leading to negative cognitive patterns and therefore depressive symptoms.

As a response to these early findings, later research began to explore more complex relationships between attachment and depression, addressing possible mediators such as the role of increased stress levels. Shirk et al. (2005) described an association between insecure attachment levels and maternal representation as unavailable or unsupportive and demonstrated that this relationship varied with stress-level and self-worth perceptions. In particular, they argued that insecure attachment increased the risk for depression as a result of the high stress levels and low self-worth experienced by adolescents who were insecurely attached. Moreover, they put forward the idea that in times of distress adolescents who are insecurely attached will underutilize social support which in turn contributes to depressive symptoms (Shirk et al., 2005). This finding has since been replicated across a number of studies (Abela, Parkinson, Stolow, Starrs, 2009; Resitifo \& Bögel, 2009; Shirk et al., 2005).

\section{Parental Depression}

These studies, however, were not integrative and did not examine possible mediators of the effects of maternal depression. In contrast, Miller, Warner, Wickramaratne, and Weissman 
(1999) conducted a multi-factorial study and found that maternal depression was not a direct predictor of youth depression but was only relevant when combined with maternal lowemotional availability and high maternal control. Similarly, Leve, Kim, and Pears (2005) suggested that it was maternal depression in combination with low family income that predicted youth depression.

\section{Parental Depression vs. Maternal Depression}

A subtlety that still warrants further research is the differential impact of paternal vs. maternal depression on the development of depressive symptoms in youth. Only a small number of studies have examined the unique impact of paternal depression (e.g., Kane \& Garber, 2009), and these have suggested that paternal depression is related to both externalizing and internalizing symptoms in adolescents. Notably, Marmorstein and Iacono's (2004) investigation of parental and adolescent psychopathology, found paternal depression to be less strongly related to adolescent depression than maternal depression. Similarly, Connell and Goodman (2002) found a greater paternal influence when children were older and a greater maternal influence when children were younger. Various explanations have been offered for these differential effects including that mothers traditionally have a greater role in child-rearing in general (Marmorstein \& Iacono, 2004) and a greater influence on younger children in particular since younger children may have fewer competing external influences and are in a more escalated period of growth and development than their older counterparts (Connell \& Goodman, 2002). Further research is warranted regarding the differential impacts of paternal and maternal depression on adolescent depressive symptoms.

\section{Mechanisms}


In addition to studies of the specific relationships between parental depression and adolescent depression, there have also been studies examining the mechanisms underlying these associations. For example, genetic factors have been shown to increase the risk of developing depression from $7 \%$ to $20-25 \%$, and they also may contribute to the development of specific depression-related vulnerabilities such as behavioural inhibition, shyness, or low self-esteem (Goodman and Gotlib, 1999). Other factors have also, however, been shown to influence the intergenerational transmission of depression. Parents who are depressed may have difficulties responding to their children's emotional environment and/or to practicing effective parenting skills (Resitifo and Bögel, 2009). In addition, as noted previously, depression in parents increases the likelihood of children developing insecure attachment (Garber \& Kane, 2009), which is another risk factor for depression. Moreover, children may be more likely to be exposed to stressful events as a result of their parents' conditions which can also increase the risk of depression (Abela, Skitch, Auerbach, and Adams, 2005). Lastly, parental depression is also speculated to contribute to adolescent depression through modelling of negative cognitive behaviour (Fisak Jr. \& Grills-Taquechel, 2007; Resitifo \& Bögel, 2009; Spence et al., 2002). In summary, while many hypotheses have been generated regarding the intergenerational transmission of depression, the evidence required to specify a comprehensive set of developmental pathways is lacking. Most likely, more factors than have been studied will need to be understood given the complexities of the family context and the dynamic nature of relationships over time. Moreover, more integrative investigations will likely be necessary to understand the interrelationships between multiple factors (Connell and Goodman, 2002; Weissman et al., 1997) as well as to better comprehend the impact of parental comorbid disorders on adolescent depressive symptoms (Marmorstein and Ioacono, 2004). 


\section{Conflict and Divorce}

Between 1960 and 1980, divorce rates escalated drastically, causing an increase in the amount of attention dedicated to the phenomenon in academia (Hoyt, Cowen, Pedro-Carroll, and Alpert-Gillis, 1990). Since this initial interest, research has continued to develop, even as the divorce rates have stagnated. In 2008, in Canada, approximately 41 percent of marriages ended in divorce (Statistics Canada, 2011). Early studies were primarily cross-sectional and did not consider mediating factors, hidden mechanisms, or temporal analyses. In addition, many of these studies were suspected to be representative of only a small subset of middle-class EuropeanAmericans (Lansford, 2009). Over time, however, more complex methodologies and research models has become common. Through these more comprehensive studies, information on how different secondary stressors as well as pre-divorce circumstances impact children of divorcing parents has become increasingly available. A relationship between divorce and depressive symptoms in adolescents was identified early on (Hoyt et al.,1990), but it was limited to the conclusion of a simple correlation. Later studies used longitudinal designs and examined divorce as a process rather than as a single event, taking into consideration a range of factors that could impact the relationship between divorce and adolescent depression. Socio-economic status (SES) is one significant factor. Divorce can impact child outcome through its effects on financial resources especially for children living in a single mother income households (Lansford, 2009). Aseltine (1996) also argued that financial stressors actually play a greater role in predicting adolescent depressive symptoms than family conflict, speculating that another force at play is the fact that financial stress may cause depressive symptoms in parents, which could in turn affect the child's development. Family conflict, however, has been interpreted by other researchers to hold high significance in affecting child's adjustment during a divorce (Amato, 2001; Lansford, 
2009), and relationships between levels of family conflict (without divorce) and adolescent depression have been analyzed thoroughly in previous literature (e.g., Sheeber et al., 1997). Hetherington and Stanley-Hagan (1999) analyzed this further, stating that the type of conflict is also relevant; conflicts where the child feels caught in the middle or directly exposed to physical or verbal friction are especially deleterious.

Notably some studies have also demonstrated that divorce may actually mitigate the problems that children experience (Aseltine, 1996). Amato (2001) suggests that this is only present in high-conflict marriages, where the dissolution of the relationship results in more peaceful circumstances for the children, providing them with relief. In low-conflict marriages, the conditions of children in divorce situations worsened because the separation was more likely to be viewed as abrupt and unexpected (Amato, 2001). Another factor that has been examined in efforts to understand the impact of divorce on child outcomes has been remarriage. Storksen, Roysamb, Torbjorn, and Tambs (2005) found no difference in the risk of youth depression among children whose parents remarried compared to children whose parents stayed single while Aseltine's (1996) data concluded that remarriage decreased the risk of depression in youth compared to children whose parents stayed single. One possible explanation for these discrepancies is the differences in age of the participants with Aseltine (1996) investigating youth between the ages of 14-17 years and Storksen et al. (2005) focusing on children between the ages of 4-7 years. The differences could also be a result of differences in methodology. Lastly, there is evidence that the number of times a family is blended is a predictor of poor child adjustment due to relational discontinuity (Saint- Jacques et al., 2006). This discontinuity may result in difficulties with emotional security, which may in turn lead to adjustment difficulties (Davies \& Cummings, 1994). 


\section{Family Climate}

Family climate is a term used to describe the family context, including family conflict, support, warmth, control, and autonomy. Since family conflict has been discussed above, this review will focus more on the other effects associated with family climate. High levels of family support have been observed to mediate the effects of stress on internalizing symptoms in youth (Barrera Jr. and Garrison-Jones, 1992). The stress-buffering model asserts that social support mitigates the relationship between stressful life events and depression (Stice, Ragan, and Randall, 2004). It was also perceived that there was a negative relationship between satisfaction with supportiveness of family, particularly fathers, and depressive symptoms (Barrera Jr. and Garrison-Jones, 1992).

Control and autonomy are two other factors that have been found related to the development of depressive symptoms in youth. Harsh discipline has been shown to increase boys' internalizing difficulties (Leve et al., 2005). Similarly, Resitifo and Bögel's (2009) study highlighted mechanisms of child outcomes related to autonomy and control in a parent-child relationship. Autonomy has been defined as the primary objective of adolescence and includes the need for adolescents to negotiate conflicts and establish independence from their parents (Resitifo and Bögel, 2009). Therefore, a certain degree of conflict is expected and necessary in a healthy parent-adolescent relationship (Resitifo and Bögel, 2009). In families where there is a high degree of existing stress or conflict, the family may not be able to tolerate this added autonomy-seeking distress, which has been observed to result in increased levels of internalizing behaviour in adolescents.

\section{Same-Sex Parents}


Another topic that warrants further research is that of the effect of non-heterosexual relationships on the depression of adolescents. It has often been assumed that the development of children is impacted by their parents' sexual orientation, but several studies have demonstrated no significant differences in adjustment between the children of same-sex parents and oppositesex parents (Chan, Raboy, \& Patterson, 1998; Golombok et al., 2003; Patterson, 2006;

Wainright, Russell, \& Patterson, 2004). These conclusions suggest that we could expect parental depression in same-sex marriages to have similar impacts on children as parental depression in heterosexual parents. Indeed, many studies have found that like children with heterosexual parents, marital problems and the parent-child relationship are the most prominent factors in determining child adjustment for children with same-sex parents (Chan et al., 1998; Patterson, 2006). There is, however, a paucity of literature regarding child outcomes in the context of samesex parenting and questions have been raised about the representativeness of study samples to date (e.g., primarily self-identified volunteers, specific conception types; Golombok et al., 2003). Accordingly, it is suggested that more research is needed and future research examine a broad range family constellations and types of conception (adoption, surrogate, natural birth).

\section{Siblings}

Cross-cultural research shows that siblings are central in the lives of children and adolescents globally and remain among the most important figures in their lives into adulthood and senior years_(McHale, Updegraff, and Whiteman, 2012). Not only do siblings spend more time with each other than parents or peers outside of school (Whiteman and Christiansen, 2008), but they are a unique source of support for many adolescents, acting as a middle-ground between friends and parents. Not unlike parental figures, siblings are reliable, available, and accessible resources that adolescents find helpful when dealing with stress, but they are often sought out in 
the place of parents for matters such as dating, risk-taking, and sex (Yeh, 2001). As a result, they are similar to an adolescent's closest friends. Siblings also become important figures as adolescents strive to increase their autonomy from parents but still desire a family connection (Yeh, 2001).

Given the importance of sibling relationships on adolescent development, numerous studies have been conducted regarding the relationship between sibling structure, relationship quality, and conflict upon adolescent adjustment (Vogt-Yuan, 2009; Desha, Nicholson, and Ziviani, 2010; Richmond, Stocker, and Rienks, 2005). However, in comparison to research focused on the effects of parenting and parental depression, the number of studies are limited (McHale, Updegraff, and Whiteman, 2012). In addition, only a small number of investigations have been devoted to analyzing the qualities of siblings as they relate specifically to depression in adolescents (Richmond, Stocker, and Rienks, 2005).

Nevertheless, some studies examining general adjustment do provide information about the risk of internalizing symptoms in adolescents with respect to siblings. For example, a direct relationship between negative sibling relationships and internalizing behaviour has been demonstrated (Richmond, Stocker, and Rienks, 2005; Shanahan, McHale, Crouter, and Osgood, 2008; Morgan, Shaw, and Olino, 2012) whereas other studies determined that this relationship was indirect (Yeh, 2001; Yeh and Lempers, 2004). Yeh (2001) found that positive sibling relationships improved adolescent self-esteem, peer friendships, and resistance to stressful situations, which in turn decreased the risk for internalizing symptoms (Robinson, Garber, and Hilsman, 1995). On the other hand, Roberts (1985) found that siblings' perceptions of their sibling relationships as competitive or rivalrous due to perceived differential treatment by parents, were associated with increased depressive symptoms and lower levels of self-esteem. 
Influence of Family Context

Similarly, Brody (1998) found that anger, jealousy, and low self-esteem could result from parental differential treatment among siblings. It was found that when children perceived an unfair treatment among siblings that there was an increase in depressive symptoms for that child (Shanahan, McHale, Crouter, and Osgood, 2008; Richmond, Stocker, and Rienks, 2005; VogtYuan, 2009). It is important, however, not to neglect the possibility for negative sibling influences. Although not directly related to depression, it is worth mentioning that research has shown that sibling socialization of alcohol and substance use, aggressive behaviour, and negative cognitions can occur (McHale, Updegraff, and Whiteman, 2012; Yeh, 2001). The mechanisms are likely similar to those of positive social behaviour such as modeling and imitation.

Destructive sibling relationships have also been associated with poor social functioning and internalizing problems in boys (Morgan, Shaw, and Olino, 2012). This correlation is suspected to be mediated by the closeness of the sibling relationship, with closer siblings having a greater influence on each other than siblings who are not as close (Brody, 1998). These interpretations, however, must be considered with caution since there are several limitations in the studies examined. Many researchers analyzed only a small subgroup of adolescents, one example being Morgan, Shaw, and Onlino's (2012) investigation that was limited to adolescent boys in low-income families. Shanahan, McHale, Crouter, and Osgood's (2009) investigation was limited to maritally intact, two-parent families with two siblings in middle childhood who were generally European American and socioeconomically stable.

The mechanism of positive sibling relationships improving friendships has also been analyzed as a possible indirect link to depression among adolescents as peer rejection has been shown to predict a range of problematic outcomes in children (Stocker and Dunn, 1990; Roberts, 1985). Stocker and Dunn (1990) suggest that children learn particular behaviours in relationships 
with their parents and siblings and that these behaviours then generalize to interactions with peers and friends. Yeh (2001) also found a bidirectional relationship, one that most likely was not discovered by Stocker and Dunn (1990) due to the investigation's cross-sectional nature that suggested that as sibling relationships improve, so do peer relationships and vice versa.

Whiteman and Christianson (2008) speculate that this relationship is a result of socialization and modeling of siblings, while Yeh (2001) suggests that it originates from the opportunities siblings have for social cognitive development and the learning of social skills in early childhood. Stocker (1990) found in his investigation, however, that there were only modest associations between sibling relationship quality and friendships. He suggested that the mechanisms were more complex, suggesting a large influence of child temperament and hidden mechanisms. For instance, Stocker (1990) suggested that an increase in conflict between siblings could cause adolescents to seek support elsewhere, improving the quality of friendships outside the family. In addition, heightened conflict could provide children with the opportunity to develop social skills, thus improving future friendships (Yeh, 2001).

Most studies, however, concluded that the main role of siblings was to act as a buffer when dealing with high-stress or negative situations (East and Rook, 1992). In a study analyzing the interactions between social skills, emotional vulnerability, and sibling relationship quality, it was found that boys with high emotional vulnerability had fewer internalizing problems when they had positive sibling relationships (Morgan, Shaw, and Olino, 2012). This suggests that siblings who provide support can moderate the effects of high emotional vulnerability. Richmond, Stocker, and Rienks (2005) analyzed 136 sibling pairs for internalizing and externalizing behaviour and found that improvements in the sibling relationships can help to alleviate stress in the transition to adolescence. East and Rook (1992) also determined in their 
investigation of 450 sixth-graders that there was a small ameliorating role of sibling relationship on the adjustment of isolated children, reinforcing the notion that siblings can act as a mediator for stressful environments thus providing a sense of support.

Although studies have worked to decipher the connection between sibling relationships and adolescent depression, it is important to consider how the roles of siblings may change over time, moderating these previously-found relationships. A significant factor to be analyzed is the changing role of siblings as children become adolescents. Buhrmester and Furmam (1990) found that as children age, their relationships with siblings become more egalitarian with less difference between the roles of older and younger siblings. They also lose intensity, with less conflict occurring and even at times less warmth reported. However, the study showed only moderate effect sizes, indicating that emotional attachment remains strong throughout adolescence even as the amount of time spent together decreases. McHale and colleagues suggest that social cognitive development may provide for more depth in sibling relationships even as companionship declines through adolescent years (McHale, Updegraff, and Whiteman, 2012).

Gender of siblings was also considered in several investigations, and most studies supported that sister-to-sister relationships showed the most warmth and support (Yeh, 2001; Vogt-Yuan, 2009; Shanahan, McHale, Crouter, and Osgood, 2008; Roberts, 1985). Differences in age may also be important. While some research has found that age spacing between siblings has a minimal effect on emotional and social development and sibling interaction (Brody 1998, Abramovich, Corter, \& Lando, 1979), Minnett and colleagues' (1983) work did find some differences such that children were more aggressive with a close in age sibling than a widelyspaced sibling and more affectionate with a widely-spaced sibling than a closely-spaced sibling. This discrepancy may be explained in part, however, by the age of the children in the samples. 
The children in the Minnett et al (1979) paper were 7 to 8 years old, whereas the children in the Abramovich et al (1979) study were toddlers and pre-schoolers.

Sibling research has been limited by a number of methodological factors. For example, there is a paucity of research regarding differences in the impact of sibling relationships on mental health among socio-economic groups, cultures, and location. Further research should investigate how these factors could be possible moderators to sibling relationships. For example, Latin Americans have a culture of family closeness that could moderate the feelings and actions of siblings towards one another. In addition, many studies were also cross-sectional, ruling out the possibility of identifying bidirectional or inversely directional effects (Vogt-Yuan, 2009; East and Rock, 1992; Whiteman and Christiansen, 2008). Lastly, many of the studies reviewed here only analyzed two-sibling relationships, either choosing families with only two children or eliminating other children from the analysis (Yeh, 2001; Vogt-Yuan). This limitation may have led to conclusions that are not relevant to families with multiple children. Research examining the network of sibling relationships in families with more than 2 children is needed.

\section{Methodological Considerations}

It is also worth addressing the validity and methodology of the aforementioned studies. Many of the studies that focused on the internalizing behaviour in youth are based upon selfreport data. This methodology can be useful, especially when including a large number of participants as it allows the researcher to investigate the perceptions of different participants. Unlike clinician-administered interviews, youth self-report measures typically do not require specialized training for scoring and interpretation of results and require less work by the clinician (Kline et al., 2012). Self-report measures have also been found to have convergent validity with diagnostic interviews for children and adolescents (Garrison, Addy, Jackson, McKeown, \& 
Waller, 1991; Weinstein, Noam, Grimes, Stone, \& Schwab-Stone, 1990). For example, Spence et al. (2002) used a self-report measure to investigate the impact of maternal anxiety and depression on youth by surveying both mothers and daughters, in order to understand the differences in their unique perspectives. Although test-retest reliability for this adolescent self-report scale is high, (Achenbach, 1991), self-report measures in general warrant caution, as they may reflect a reporting bias. This potentially contributed to Spence et al.'s (2002) study when there was a low level of agreement among the informants. Using self-reports from adolescents with depression could have exacerbated negativity as a result of the negative cognitive patterns of the depressed youth. Therefore, it is desirable to have both observational and self-report data in order to investigate the relationship between the different perspectives and to try to land on an externally valid understanding of the relationship (Kobak, Cole, Fleming, Ferenz-Gillies, and Gamble, 1993). Often the recording of perception of a situation from depressed participants can be a prominent indicator of depression, but these perceptions cannot be depicted without a comparison to reality.

Therefore, although there are multiple studies that reflect the notion that insecure attachment is related to depressive symptoms, there has been no supportable conclusion as to the specific causal relationship between the two variables. This is also due to the proliferation of cross-sectional studies as opposed to longitudinal studies which are more operational in determining specific mechanisms at work. In addition, the question warrants further research, as negative bias could be a significant mediator in the results found in these analyses.

\section{Conclusion}

This review serves to highlight several aspects of the current literature focused on the relationship between family situation and the development of adolescent depression, including 
the need for more longitudinal, observational, and integrative studies to research certain elements of the relationship further. Specifically, there is a dearth in the literature regarding the role that fathers play in the family system and the role that gender plays in a variety of scenarios. This review is also limited to discussions of depression, and does not address the ways in which different disorders interact with different risk factors. A focus on comorbidity and interactions between disorders is suggested in further research. Given the fact that $75 \%$ of mental disorders develop before the age of twenty-four (Mental Health Commission of Canada, 2011), it is imperative that our energy and research be targeted towards the younger portion of our population. We are also hopeful, however, that with focused and continued effort, effective treatment strategies will be developed to meet the needs of struggling youth and families. 
Influence of Family Context

\section{References}

Abramovich, R., Corter, C., \& Lando, B. (1979). Sibling interaction in the home. Child Development, 50(4), 997-1003.

Achenbach, T. M. (1991). Manual for youth self-report and 1991 profile. Burlington: University of Vermont Department of Psychiatry.

Abela, J. R. Z., Skitch, S. A., Auberbach, R. P., Adams, P. (2005). The impact of borderline personality disorder on vulnerability to depression in children of affectively ill parents. Journal of Personality Disorders, 19(1), 68-83.

Abela, J. R. Z., Zinck, S., Kryger, S., Zilber, I., Hankin, B. L. (2009). Contagious depression: Negative attachment cognitions as a moderator of the temporal association between parental depression and child depression. Journal of Clinical Child and Adolescent Psychology, 38(1), 16-26.

Amato, P. R. (2001). Children of divorce in the 1990s: An update of the Amato and Keith (1991) meta-analysis. Journal of Family Psychology, 15(3), 355-370.

Armsden, G. C., McCauley, E., Greenberg, M. T., Burke, P. M., and Mitchell, J. R. (1990). Parent and peer attachment in early adolescent depression. Journal of Abnormal Child Psychology, 18(6), 683-97.

Aseltine Jr., R. H. (1996). Pathways linking parental divorce with adolescent depression. Journal of Health and Social Behavior, 37(2), 133-148.

Barrera Jr., M., Garrison-Jones, C. (1992). Family and peer social support as specific correlates of adolescent depressive symptoms. Journal of Abnormal Child Psychology, 20(1).

Bowlby, J. (1980). Attachment and loss. Loss: Sadness and depression, Vol. 3. New York: Basic Books. 
Brody, G. H. (1998). Sibling relationship quality: Its causes and consequences. Annual Review of Psychology, 49(1), 1-24.

Buhrmester, D., Furman, W. (1990). Perceptions of sibling relationships during middle childhood and adolescence. Child Development, 61(5), 1387-1398.

Chan R. W., Raboy B., Patterson C. J. (1998). Psychosocial adjustment among children conceived via donor insemination by lesbian and heterosexual mothers. Child Development, 69(2), 443-457.

Connell, A. M., Goodman, S. H. (2002). The association between psychopathology in fathers versus mothers and children's internalizing and externalizing behavior problems: A metaanalysis. Psychological Bulletin, 128(5), 746-773.

Davies, P. T., \& Cummings, E. M. (1994). Marital conflict and child adjustment: An emotional security hypothesis. Psychological Bulletin, 116(3), 387-411.

Dekker, M. C., Ferdinand, R. F., van Lang, N. D. J., Bongers, I. L., van der Ende, J., Vurhulst, F. C. (2007). Developmental trajectories of depressive symptoms from early adolescence to late adolescence: Gender differences and adult outcome. Journal of Child Psychology and Psychiatry, 48(7), 657-666.

Desha, L. N., Nichols, J. M., Ziviani, J. M. (2011). Adolescent depression and time spent with parents and siblings. Social Indicators Research, 101(2), 233-238.

East, P. L., Rook, K. S. (1992). Compensatory patterns of support among children's peer relationships: A test using school friends, nonschool friends, and siblings. Developmental Psychology, 28(1), 163-172. 
Festinger, T., \& Jaccard, J. (2012). Suicidal thoughts in adopted versus non-adopted youth. A longitudinal analysis in adolescence, early young adulthood, and young adulthood. Journal of the Society for Social Work and Research, 3(4), 280-295.

Fisak Jr., B., Grills-Taquechel, A. E. (2007). Parental modeling, reinforcement, and information transfer: Risk factors in the development of child anxiety? Clinical Child and Family Psychology, 10(3).

Garrison, C. Z., Addy, C. L., Jackson, K. L., McKeown, R. E., \& Waller, J. L. (1991). The CES$\mathrm{D}$ as a screen for depression and other psychiatric disorders in adolescents. Journal of the American Academy of Child and Adolescent Psychiatry, 30(4), 636-641.

Golombok, S., Spencer, A., Rutter, M. (1983). Children in lesbian and single-parents households: Psychosocial and psychiatric appraisal. Journal of Child Psychology and Psychiatry, 24(4), 551-572.

Golombok, S., Perry, B., Burston, A., Murray, C., Mooney-Somers, J., Stevens, M., and Golding, J. (2003). Children with lesbian parents: A community study. Developmental Psychology, 39(1), 20-33.

Goodman, S. H., \& Gotlib, I. H. (1999). Risk for psychopathology in the children of depressed mothers: A developmental model for understanding mechanisms of transmission. Psychological Review, 106, 458-490.

Government of Canada (2006). The human face of mental health and mental illness in Canada 2006. Retrieved from http://www.phac-aspc.gc.ca/publicat/humanhumain06/pdf/human_face_e.pdf 
Hammen, C. L., Burge, D., Daley, S. E., Davila, J., Paley, B., Rudolph, K. D. (1995). Interpersonal attachment cognitions and prediction of symptomatic responses to interpersonal stress. Journal of Abnormal Psychopathology, 104(3), 436-443.

Hammen, C., \& Brennan, P. (2001). Depressed adolescents of depressed and nondepressed mothers: Tests of an interpersonal impairment hypothesis. Journal of Consulting and Clinical Psychology, 69, 284-294.

Hammen, C., Brennan, P. A. (2003). Severity, chronicity, and timing of maternal depression and risk for adolescent offspring diagnosis in a community sample. Archives of General Psychiatry, 60.

Hoyt, L. A., Cowen, E. L., Pedro-Carroll J. L., \& Alpert-Gillis L. J. (1989). Anxiety and depression in young children of divorce. Journal of Abnormal Child Psychology, 19(1), 26-32

Kandel, D. B., \& Davies, M. (1982). Epidemiology of depressive mood in adolescents. Archives of General Psychiatry, 39, 1205-1212.

Kane, P.P., \& Garber, J. (2009). Parental depression and child externalizing and internalizing symptoms: Unique effects of fathers' symptoms and perceived conflict as a mediator. Journal of Child and Family Studies, 18(4), 465-472.

Kessler, R. C. (2003). Epidemiology of women and depression. Journal of Affective Disorders, $74(1), 5-13$.

Kline, E., Wilson, C., Ereshefsky, S., Denenny, D., Thompson, E., Pitts, S. C., ... Schiffman, J. (2012). Psychosis risk screening in youth: A validation study of three self-report measures of attenuated psychosis symptoms. Schizophrenia Research, 141(1), 72-77. 
Influence of Family Context

Kobak, R. R., Cole, H. E., Ferenz-Gillies, R., Fleming, W. S., \& Gamble, W. (1993). Attachment and emotion regulation during mother-adolescent problem solving: A control theory analysis. Child Development, 64(1), 231-245.

Lamb, M. E. (1975). Fathers: Forgotten contributors to child development. Early Human Development. 18, 245-266.

Lansford, J. E. (2009). Parental divorce and children's adjustment. Perspectives on Psychological Science, 4(2).

Leve, L. D., Hyoun, K. K., Pears, K. C. (2005). Child temperament and family environment as predictors of internalizing and externalizing trajectories from ages 5-17. Journal of Abnormal Child Psychology, 33(5), 505-520.

Marmorstein, N. R., \& Iacono, W. G. (2004). Major depression and conduct disorder in youth: Associations with parental psychopathology and parent-child conflict. Journal of Child Psychology and Psychiatry, 45, 377-386.

McHale, S. M., Updegraff, K. A., Whiteman, S. D. (2013). Sibling relationships. Handbook of Marriage and Family (15).

Miller, L., Warner, V., Wickwamaratne, P., \& Weissman, M. (1999). Self-esteem and depression: Ten year follow-up of mothers and offspring. Journal of Affective Disorders, $52,41-49$.

Minnett, A. M., Lowe Vandell, D., \& Santrock, J. W. (1983). The effects of sibling status on sibling interaction: Influence of birth order, age spacing, sex of child, and sex of sibling. Child Development, 54(4), 1064-1072.

Morgan, J. K., Shaw, D. S., Olino, T. M. (2012). Differential susceptibility effects: The interaction of negative emotionality and sibling relationship quality on childhood 
Marshall \& Henderson

internalizing problems and social skills. Journal of Abnormal Child Psychology, 40(6), 885-899.

Myers Brewer, M. (2010). The effects of child gender and child age at the time of parental divorce on the development of adult depression (Doctoral dissertation). Retrieved from ProQuest Information \& Learning. (UMI 3404338)

Olsson, G. I., Nordstrom, M. L., Arinell, H., \& von Knorring, A. L. (1999). Adolescent depression: Social network and family climate-A case-control study. Journal of Child Psychology and Psychiatry, 40, 227-237.

Palacios, J., \& Brodzinsky, D. (2010). Adoption research: Trends, topics, outcomes. International Journal of Behavioral Development, 34(3), 270-284.

Patterson, C. J. (2006). Children of lesbian and gay parents. Association for Psychological Science, 15(5), 241-244.

Restifo, K., Bögels, S. (2009). Family processes in the development of youth depression: Translating the evidence to treatment. Clinical Psychology Review, 29, 294-316.

Richmond, M. K., Stocker, C. M., Rienks, S. L. (2005). Longitudinal associations between sibling relationship quality, parental differential treatment, and children's adjustment. Journal of Family Psychology, 19(4), 550-559.

Roberts, E. A., (1985). The relationship of the sibling bond to self-esteem. (Doctoral Dissertation).

Robinson, N. S., Garber, J., Hilsman, R. (1995). Cognitions and stress: direct and moderating effects on depressive versus externalizing symptoms during the junior high school transition. Journal of Abnormal Psychology, 104(3), 453-463. 
Influence of Family Context

Saint-Jacques, M.C., Cloutier, R., Pauzé, R., Simard, M., Gagné, M. H., \& Poulin, A. (2006). The impact of serial transitions on behavioral and psychological problems among children in child protection services. Child Welfare, 85(6), 941-964.

Sander, J. B., \& McCarty, C. A. (2005). Youth depression in the family context: Familial risk factors and models of treatment. Clinical Child and Family Psychology Review, 8(3), 203-219.

Shanahan, L., McHale, S. M., Crouter, A. C., Osgood, D. W. (2008). Linkages between parents' differential treatment, youth depressive symptoms, and sibling relationships. Journal of Marriage and Family, 70(2), 480-494.

Sheeber, L., Hops, H., Alpert, A., Davis, B., Andrew, J. (1997). Family support and conflict: Prospective relations to adolescent depression. Journal of Child Psychology, 25(4), 333344.

Shirk, S. R., Gudmundsen, G. R., \& Burwell, R. A. (2005). Links among attachment-related cognitions and adolescent depressive symptoms. Journal of Clinical Child and Adolescent Psychology, 34, 172-181.

Spence, S. H., Najman, J. M., Bor, W., O’Callaghan, M. J., Williams, G. M. (2002). Maternal anxiety and depression, poverty, and marital relationship factors during early childhood as predictors of anxiety and depressive symptoms in adolescence. Journal of Child Psychology and Psychiatry, 43(4), 457-469

Statistics Canada. (2011). Divorces and crude divorce rates, Canada, provinces and territories, annual. 
Stice, E., Ragan, J., \& Randall, P. (2004). Prospective relations between social support and depression: Differential direction of effects for parent and peer support. Journal of Abnormal Psychology, 113, 155-159.

Stocker, C., Dunn, J. (1990). Sibling relationships in childhood: Links with friendships and peer relationships. British Journal of Developmental Psychology, 8(3), 227-244.

Stocker, C. M. (1994). Children's perceptions of relationships with siblings, friends, and mothers: Compensatory processes and links with adjustment. Journal of Child Psychology and Psychiatry, 35(8), 1447-1459.

Storksen, I., Roysamb, E., Moum, T., Tambs, K. (2005). Adolescents with a childhood experience of parental divorce. Journal of Adolescence, 28, 725-739.

Strohschein, L. (2005). Parental divorce and child mental health trajectories. Journal of Marriage and Family, 67, 1286-1300.

Uphold-Carrier, H., \& Utz, R. (2012). Parental Divorce Among Young and Adult Children: A Long-Term Quantitative Analysis of Mental Health and Family Solidarity. Journal of Divorce \& Remarriage, 53(4), 247-266.

Vogt Yuan, A. S. (2009). Sibling relationships and adolescents' mental health: The interrelationship of structure and quality. Journal of Family Issues, 30(9), 1221-1244.

Waldinger, R. J., Vailland, G. E., Orav, E. J. (2007). Childhood sibling relationships as a predictor of major depression in adulthood: A 30-year prospective study. The American Journal of Psychiatry, 164(6), 949-954.

Wainright, J. L., Russell, S. T., Patterson, C. J. (2004). Psychosocial adjustment, school outcomes, and romantic relationships of adolescents with same-sex parents. Child Development, 75(6), 1886-1898. 
Influence of Family Context

Weinstein, S. R., Noam, G. G., Grimes, K., Stone, K., \& Schwab-Stone, M. (1990). Convergence of DSM-III diagnoses and self-reported symptoms in child and adolescent inpatients. Journal of the American Academy of Child and Adolescent Psychiatry, 29(4), 627-634.

Weissman, M. M., Warner, V., Wickramaratne, P., Moreau, D., \& Olfson, M. (1997). Offspring of depressed parents. 10 years later. Archives of General Psychiatry, 54(10), 932-940.

Whiteman, S. D., Christianson, A. (2008). Processes of sibling influence in adolescence: Individual and family correlates. Family Relations, 57(1), 24-34.

Yeh, H. (2001). The influences of sibling relationships in adolescence. (Doctoral Dissertation).

Yeh, H., Lempers, J. D. (2004). Perceived sibling relationships and adolescent development. Journal of Youth and Adolescence, 33(2), 133-147. 